\title{
Intercultural identity transformations among Japanese learners of English
}

Capobianco, Paul $\bowtie$

University of Iowa, USA (Paul-capobianco@uiowa.edu)

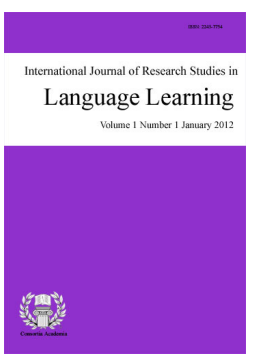

ISSN: 2243-7754

Accepted: 17 August 2016

\section{Abstract}

This paper examines how Japanese learners of English undergo identity transformations as they engage in the continued process of their language study. It will explain the material and conceptual changes that learners experience, demonstrate how learners develop greater intercultural orientations as a result of their study, and highlight the important role that meaningful interactions play in the progression of identity development. Concerning the lattermost objective, this paper suggests that there are at least two qualitatively different acts that account for different types of identity transformations in second language learners. The first is the act of studying a new language and the second is participation in meaningful interactions with members of the target language community. Each act serves as a discrete process through which revelations about personal identity can be realized. This paper establishes these arguments based upon intercultural communications theory, poststructuralist studies into second language acquisition, and the overall affective processes related to language learning.

Keywords: language learning; identity; intercultural communication; English as a Foreign Language; Japan; interpersonal communication 


\section{Intercultural identity transformations among Japanese learners of English}

\section{Introduction}

Learning a new language has been shown to affect how individuals think of themselves and their personal identity. Despite the diverse circumstances through which individuals find themselves acquiring a new language, their experiences inside and outside the classroom play a profound role in shaping the ways they identify themselves in their idiosyncratic sociocultural contexts (Kim, 2001; Norton, 2000). This process is often conditioned by affective variables that influence both the learner's language acquisition and identity trajectory (Burns \& Roberts, 2010; Duff, 2015; Hulsen, de Bot, \& Weltens, 2002). Therefore, the process of learning a language is much more than a unidirectional acquisition of pragmatic skills; it is also a highly personalized process capable of engendering transformations in the ways individual learners' conceptualize their understandings of self-identity.

Language itself naturally functions as a means through which individuals are identified and establish identities. Speaking a particular language, dialectic, or any form of linguistic variation indexes membership into some cultural, linguistic, social, or socioeconomic community (Ochs, 1996), which often communicates important elements of personal and/or collective identification. Michele Koven (2007, p. 6) explains that "different ways of talking...become not just superficial fluctuations of a single 'core,' but tools that perform identity, central components of people's experience, and performance of who they are.” As learners gradually acquire the skills necessary for communication, and actively partake in interactions with members of the target language culture, their ways of conceptualizing the world are challenged and they begin to incorporate new elements from their target language and culture into their own sense of personhood (Byrd \& Byrd, 2013; Dewaele, 2014; Kim, 2001). Learners become more sensitive to other cultures and begin to reformulate their identities in ways that blend into them elements of their target language community and culture.

In recent decades, scholarship on language acquisition has examined this transformation in greater detail. These works have underscored the fragmented and problematic nature of identity construction and development, as well as how the trajectory of identity is complicated by the acquisition of and exposure to new language and cultural skills (Cook, 2002; Kim, 1994, 2001; Kinginger, 2004; Norton, 2000; Ting-Toomey, 2005). Language learning is said to induce changes to already malleable self-understandings and the identities that emerge from these conditions are seen as more dynamic and more flexible (Gao, 2007; Kim, 1994). Given that there are a large number of factors that influence the acquisition process, such as personal (Brown, 2000), structural/environmental (Norton, 2000), and motivational (Dörnyei \& Schmidt, 2001), amongst others, the potential outcomes of language learning induced identity (re)construction are inexhaustive. Such conditions demand greater inquiry into how learning a language influences personal identity development, as do the factors that influence how these identities operate.

Drawing on ethnographic data collected from 2013-2015, this paper will demonstrate how language study provides new opportunities for identity construction amongst Japanese learners of English. Specifically, it will (1) describe some of the material and conceptual changes that occur as Japanese learners progress in their study, (2) demonstrate how Japanese learners develop a more intercultural sense of self-understanding as a result of their language study, and (3) highlight the important role of interaction in the process of establishing a new identity in relation to language learning. Regarding the lattermost objective, this paper suggests that there are at least two qualitatively different acts that account for identity transformation in second language learners. The first is the act of studying a new language itself and the second is the participation in perceived meaningful interactions with members of the target language community. Each serves as a discrete process through which revelations about personal identities may be realized. 


\section{Language learning and identity}

Scholarship from diverse disciplines has shown there is a strong correlation between language learning and identity. Language learners and multilinguals are said to develop different identities based on their experiences learning, utilizing, and expressing themselves in two (though perhaps more) different languages (Byram, 1997; Dewaele, 2014; Kim, 2001; Kinginger, 2004; Koven, 2007; Norton, 2000). H. Douglas Brown (2000, p. 147) states that "meaningful language acquisition involves some degree of identity conflict as language learners take on a new identity with their newly acquired competence." Zhu Hua (2013, p. 116) observes that "once a person begins to learn a new language and culture, the new language and culture will have an impact on the learner's first language and culture as well. A new identity and set of values will develop alongside the development of linguistic knowledge." Similarly, Jane Jackson (2008, p. 34) suggests that "when we learn a language, we are also learning a culture and forming our sense of self (identity)." Language learning endeavors inherently have some impact on how individuals perceive of themselves, which carries implications for their learning outcomes and understandings of personal identity.

Recently, poststructuralist scholars of second language acquisition have attempted to highlight the inherently complicated nature of identity (Cook, 2002; Kinginger, 2004; Norton 2000; Pavlenko \& Blackledge, 2004; Pavlenko \& Lantolf, 2003). Rather than seeing identities as fixed and stable, these authors have emphasized identity's haphazard, fragmented, and subjective character. An individual's understanding of identity is seen as shaped by numerous overlapping and conflating variables that account for particular self-understandings within and in relation to their sociocultural environment. Thomas Ricento (2005, p. 895) notes that "identity is theorized as a contingent process involving dialectic relations between learners and the various worlds and experiences they inhabit and which act on them." Through language learning, a more diverse set of worldviews is amalgamated into an individuals' sense of self and, as this complexity is realized, there emerge more dynamic ways of understanding who learners are. Analyzing these identities therefore requires consideration of the fragmented and multifaceted ways learners see themselves as a result of their language study.

Friederike Klippel (1994, p. 54) notes that "both the other and the self are changed in the course of...interaction." Likewise, Andrea Simon-Maeda states that self-identity "is not a static, preexisting entity but rather evolves through a dialectical relationship between different ways of interacting and speaking in the world" (Simon-Maeda, 2011, p. 17). Identity is recognized and constructed through interactions with others (Duff, 2012; Ting-Toomey, 1997, 2005; Zaharna, 1989). It is not just a standalone entity that is asserted and uncritically accepted but instead it is developed through interactions with other people. This is true both in L1 and L2; one need not be speaking another language to recognize that their identity is shaped through the interactions they have (Jenkins, 2008; Norton, 2000). Interpersonal communication thus becomes an active site through which this identity negotiation unfolds. It is language learning itself that initiates this change but the actual implementation of linguistic skills that facilitates further identity transformations.

One of the most lucid accounts of how language learning affects identity, and that most efficaciously demonstrates the aforementioned theorizations, has been presented by Celeste Kinginger (2004) in her study of "Alice," a "non-traditional" American adult learner of French who participated in a study abroad program in France. Alice began studying French because she was enticed by the opportunity to recreate herself as a French speaker and one that participates in what she perceived to be a more sophisticated French culture. Alice's experience was replete with highs and lows as she struggled to come to terms with her "French Self." Throughout this process, her identity underwent many incarnations; Kinginger explains that Alice's "images of France and of herself as a student and speaker of French were repeatedly challenged" during her tenure abroad (Kinginger, 2004, p. 232). Language learning involves conscious and subconscious reflection of one's identity and the conflict of perspectives that emerge from this process provide the learner a platform through which their identities can be renegotiated (Dahl, Clementi, Heysel, \& Spenader, 2007). Ultimately, Kinginger describes Alice's use of French as a way of "reorienting herself in the world," where she drew upon personal experiences in France to establish a novel and more critical understanding of her identity than had previously existed 
(Kinginger, 2004, p. 240). This demonstrates that there is a processural relationship between language learning and self-identity. It also shows how learners actively participate in negotiating their discursive understandings of self-identity. Identity development occurs over time and through continued engagement with the language and the target language community. Thus, identities are never a "finished product," but rather are continually a work in progress whereby individual selves are perpetually being reconstructed in relation to new experiences (Kim, 2001).

Ultimately and invariably, language learning affects individuals' worldviews (Dahl et al. 2007; Dewaele 2014). As one studies a foreign language, there emerge new ways that their existing convictions are challenged. The contrasts between L1 and L2 cultures can be very different and the language acquisition process provides learners a platform upon which their own sense of identity can be renegotiated in ways that orient them towards new types of thinking (Byrd \& Byrd, 2013). Jean-Marc Dewaele (2014, p. 51) notes that "multicompetent multilinguals seem more aware and appreciative of the diversity in the world, able to consider it through the prism of their different languages and cultures." To reiterate, learning a language is not simply a unidirectional acquisition of skills but instead involves a broader and more dynamic personal change that affects many components of a person's social, psychological, and cultural understandings.

The effects of interpersonal interaction on identity development are intensified when participants come from different backgrounds and engage in "intercultural communication" (Jackson, 2008; Kim, 2001; Ting-Toomey, 2005). Conceived of broadly and briefly, intercultural communication involves interacting with actors from different cultural backgrounds. Specifically with regards to language learning, Dewaele (2014, p. 65) explains that "participation in social networks in the target community [i.e. speaking the target language] not only boosts linguistic skills but also pushes L2 users to reflect on their identities, beliefs, and practices." Therefore, "by engaging in dialogue with Others...we routinely shape and reshape our expressions as well as our senses of identity" (Jackson, 2008, p. 21, referencing Bakhtin, 1981).

When considering the identity transformations that result from language learning and intercultural communication, it is important to not view identities in terms of binaries but recognize them as being in a continual process of development. Yihong Gao has argued that as language learning continues, learners develop greater "orientations" towards their target language community (Gao, 2007; see also Qu, 2005). Rather than one form of identity replacing another, the learning process allows individuals to incorporate into their sense of being components from a greater range of cultures. This manifests in what Young Yun Kim has defined as an "intercultural" identity (Kim, 1994, 2001, 2008), which involves grappling with and overcoming challenges in a new cultural milieu. She explains that the challenges experienced from language and culture learning "'pushes' an individual in the direction of greater intercultural learning, perceptual refinement, and a self-other orientation that is at once individuated and universalized" (Kim, 1994, p. 1). By "individuated," Kim refers to the fact that "as an individual's cultural identity evolves towards increasing interculturalness, that person's definition of self and others become increasingly less restricted by rigid cultural and social categories" (Kim, 1994, p. 14). She further notes that "the phenomenon of identity development beyond the primary cultural perimeters is closely linked with intercultural communication activities" (Kim, 1994, p. 6). Thus, there can occur a tangible shift towards an intercultural orientation as one embarks upon the study of a new language and attempts to implement their acquired skills. The following sections of this paper will consider how these changes apply to Japanese learners of English and examine what implications these changes carry materially and conceptually for interpersonal relationships.

This literature review shows that identities are inherently fragmented and multifaceted. In other words, "identity is not an objective fixed state but a complex multi-faceted phenomenon which changes throughout our life time and alternates on a daily basis as we encounter different situations. In other words, it is not static but may be formative, fluid and emergent, constructed by ourselves and others and negotiated over time and space" (McEntee-Atalianis, 2014, p. 174). This fragmentation and complexity carries important ramifications for the ways individuals conceive of and conduct themselves in given environments. This warrants further inquiry 
because it can elucidate important information about how language learning is connected to wider social trajectories and interpersonal realities. The ethnographic data below will demonstrate how Japanese learners of English reconstruct their identities, how these identities are shaped through the practical use of English, and how identities develop differently at discrete stages in the language acquisition process.

\section{Data presentation}

Data for this project was collected between 2013-2015 through interviews with Japanese learners of English. The questions examined in this paper evolved from a separate research project focusing on the broader characteristics of Japanese identity. During the course of data collection for this original project, the author recognized a trend concerning how some Japanese cited their changing identities as related to language learning and the practical application of their linguistic skills. After establishing a pattern, the author conducted follow-up interviews and inquired "how does language affect identity construction." The end result was over thirty qualitative interviews with Japanese learners dealing with the nature of their particular identity changes in relation to identity construction.

The author asked interviewees questions such as: "How has learning English affected the way that you see yourself as Japanese?" "What have your experiences learning and utilizing English entailed?" "In what ways has learning English changed your perspective of identity?" "How do you believe your language learning experience relates to the way that you see yourself today?" Interviews were conducted in Japanese and/or English. They were qualitative coded and analyzed to ascertain more general themes.

To most effectively and succinctly demonstrate the aforementioned arguments, ethnographic vignettes into the lives of four Japanese learners will be presented. These are presented because they depict most lucidly how individual learners experience identity changes throughout their study of a second language. It should be recognized that although these are just four vignettes, what these learners said applied to most other informants as well. Thus, these findings are by no means limited solely to these learners. In fact, the key arguments of this paper - that identity changed in relation to language learning occurred in dynamic ways that accounted for expanded worldviews and that learners experienced two discrete identity transformations throughout their study - were demonstrated by over half of the interviewees (at least $n=17$ for each respectively). The themes depicted below therefore resonate strongly through other interviewees. These particular people just epitomize most clearly how these changes occur in a readily comprehendible manner.

\subsection{Tetsu}

Tetsu is a man in his forties from Nagoya. He has been studying English formally for two years and previously learned some English through a private tutor and self-study books. Tetsu began learning English because of various stressful situations he was encountering in his life at the time. He was feeling depressed from a recent divorce and wanted to try something new. He believed learning English would offer him more opportunities to change his life and allow him to start seeing himself more positively. He explained:

Before I started learning English, I was very depressed. I was sad with my family and was very
stressed about my future. I felt hopeless and wanted to change myself in ways that other people
would recognize. I thought learning a language was the best way to do that, so I started to learn
with a private tutor and enrolled in formal language classes.

Tetsu hoped that by learning English, he would cultivate skills others would recognize positively and possibly access more interesting life opportunities. Looking for some kind of suffrage after a troubling divorce, learning English became an intellectual and spiritual escape his difficulties.

This escape presented him with circumstances through which he could conceive of himself more constructively: 
When I started to learn English, it was a motivating experience. Although my tutor was not good, I was a hard working student. I began to see myself differently from other Japanese people who didn't study English. I thought I was wiser and more culturally sensitive than most others. My friends who could speak English secretly became my role models.

Tetsu stated that many Japanese eschew learning about foreign cultures and don't take seriously the study of foreign languages. He drew upon this notion to reconstruct his own identity in a way that expanded his outlook on diversity and incorporated his embracement of it into his own concept of self, which he now saw as more original and dynamic. As Tetsu reestablished a more positive identity, he constantly referenced what he perceived as Japanese people's avoidance of things foreign and juxtaposed his interest in English with other Japanese who he believed did not possess such interests. Thus, his ever-improving English skills became a testament to his possession of what he sees as more diverse cultural capital.

When asked to explain how his language experience changed him, Tetsu referred to his work experience abroad. After six months of English study, Tetsu left Japan to work in Canada. While there, he experienced difficulties stemming from his lower than anticipated English ability, his continued family issues in Japan, and dissatisfaction with his work environment. However, although this situation was stressful, Tetsu is thankful for his experience because it helped him to grow into a more dynamic person:

When I used my English in Canada everyday, it was difficult and tiring. I wasn't good and I didn't understand people when they spoke back to me. The first few months were very hard. But after that I started to understand more and more of what was said and was encouraged!

In his opinion, it also helped him substantiate his more intercultural sense of self, which he constructed vis-à-vis other Japanese who lacked such experiences abroad:

Towards the end of my time in Canada, I realized how great this experience was for me. It was difficult much of the time, but finally I saw my work abroad as something good. I said to myself,

"Wow I actually spent all this time living abroad! How many other Japanese can do this?!"

By working and living abroad, Tetsu constructed his identity in juxtaposition to other Japanese, who he perceived as less sensitive to cultures outside Japan. As he grappled with the difficulties of living abroad, Tetsu became more attentive to his own identity development as a Japanese learner of English; he saw himself as Japanese but as a more intercultural Japanese capable of breaking the language barrier that many other Japanese are unable to do.

Tetsu was one of the first interviewees to draw my attention to the communicative aspects of identity transformation. He explained that it was not until he actually went to Canada, applied his language skills, experienced difficulties there, and made efforts to overcome such difficulties did feel that he emerged with a more positive self-image:

The reason I think my time abroad [distinguishes me] from other Japanese is because I used my language skills everyday. I don't think many other Japanese go abroad and have such opportunities. They stay in Japan, or if they leave, they don't use their English. My experience is different. Canadian people heard my English [and] I interacted with them. They corrected my language and I think I learned a lot from this. I even made some Canadian friends. I don't think many other Japanese can honestly say they have Canadian friends. Using my abilities brought me great happiness, even if my skills were still not very good.

The application of his English language skills in practical communication thus gave him a new means to conceptualize himself in relation to others. He constructed this new self-image in contrast to others who lacked these experiences and also emerged from his time abroad with a more dynamic understanding of himself and his relationship to others. 
In short, Tetsu's experiences studying and using English compelled him to develop a more positive identity that incorporated a wider range of intercultural elements. He underwent two discernable identity transformations in the process. The first occurred when he began studying English and the second occurred when he applied his English skills pragmatically. The first transformation, which occurred after his divorce and his commencement of formal English study, allowed him to feel more confident in himself and think himself as engaging in an act of self-improvement. The second transformation, which happened abroad and in response to the stresses of living in a foreign environment, further intensified his identity as an individual and added to the ways that he distinguished himself from other Japanese. Thus, Tetsu's identity evolved in two discrete stages marked by different experiences and differences in the ways that he applied his language skills.

\subsection{Shiori}

Shiori is middle age divorcee who lives in Fukuoka. Her story adds further substance to how communication is an essential element for arriving at various realizations related to identity. Shiori is a lower intermediate English speaker. She has been studying just over a year and has made very reasonable progress. Her reasons for starting to study English were similar to Tetsus's; she cited being upset with her life after experiencing a divorce, the ambition to pursue a new challenge, and the desire to better herself in a more dynamic way. She explained:

Going to English classes was at first a way to keep busy and challenge myself to do something new. It was attractive to be a complete beginner at something. Interacting with other students was a lot of fun and it encouraged me to keep studying.

She also noted that she began to see herself differently as she progressed in her studies:

I started to think there was something different about us students. All of my classmates were older like me, but we felt more confident about we are from taking these classes. Even though our levels are still low, we think [of] ourselves as happier people because we study hard. We look up to the teacher at our school who can speak English very well and hope one day to have the language and culture skills like he does.

Shiori and her classmates thus saw their own identities as affected by their continued study of English and the acquisition of new intercultural skills.

The most interesting component of Shiori's story is how utilizing her English skills led to a dramatic shift in how she understood herself and others. She recounted how on a recent domestic sightseeing trip, she crossed paths with a group tourists visiting the same site that she was. When she heard them speaking English, she said that she unexpectedly approached them and asked them if they had any questions about the exhibit they were viewing:

When I did this, I was really nervous. I tried to explain to them the [about the exhibit they were viewing] as best I could. I gave them some of the history about it and asked them if they were enjoying Japan. I only understood a little of their reply back to me, but it was a great interaction and it made me feel like my study has paid off!

Shiori noted this was incredibly out of character for her and that she never approached a group of foreigners like this before. However, because she was confident in her English ability and eager to apply her skills, she garnered the motivation to engage these tourists. In doing so, Shiori developed a newfound confidence in herself and her language ability. She enthusiastically stated that she hopes to do this again when the next opportunity presents itself and she hopes that her next interaction will go even better than her first.

When I inquired with her why she thought this interaction was so exciting, she explained that it was because she developed confidence in herself, but also because she realized that learning English could provide her skills she could use to meet new people and have new encounters: 
I have never interacted with a foreigner before besides in my English lessons. I have said things like "hello" to them and simple things like that, but this was the first time I had a real conversation with foreigners. When I actually spoke with them, I realized that my interest in English could be so much more than it is now. I can learn more about American culture, I can read some books, and make new friends. I think that I can experience the world much differently than I previously have.

Through interacting with foreigners, Shiori developed a new perspective of the world and a greater appreciation of the diversity the world has to offer.

Shiori also feels that this new appreciation of foreign cultures changed the ways she thought about non-Japanese people, especially those living in Japan. Whereas she previously felt that they existed in their own circles, outside and inaccessible to her own life, she believed this experience has made them more accessible:

I see foreigners often in Fukuoka. They are everywhere and there are many different types. There are many different ones and some don't speak English. I always thought that they are living in their own worlds and that because I can't speak English, probably I can't communicate with them and they don't concern me. But lately there have been more foreigners in Japan and there have been some difficulties between foreigners and Japanese. I have been more aware of them. Now, I think I can actually communicate with them! They don't seem to be so far away from me anymore and I think now that I had one interaction with them, I can have more.

By communicating with the tourists, Shiori diversified how she conceptualized foreign Otherness. She began to see foreigners as less distant from herself and more accessible in conversation and social situations because she believes that language barriers are now minimized.

Shiori's case underscores how specifically interaction can affect one's sense of self-identity. By going out of her comfort zone and using her English skills, Shiori developed more confidence in herself and in her English ability. She also cut the pragmatic and conceptual distance between her and foreign English speakers. In doing so, she developed a more intercultural comprehension of who she is as a person, which subsequently led her to develop a self-perception that is more dynamic and more sensitive to other cultures.

\subsection{Yoshi and Takeyuki}

The final vignette examines two young Japanese males, Yoshi and Takeyuki, both of whom have considerable experience living abroad. The reason for aggregating these two into one vignette is because their identity transformations are so strikingly similar. Although each possessed their own unique experience, their similarities supplement each other to substantiate the points indicated above.

Yoshi is a thirty one year old staff member at a hotel in Tokyo. About ten years ago, after experiencing depression, he wanted to do something drastically different. He decided to take a trip to Australia and Southeast Asia to get away from life in Japan. He took an English phrasebook with him and departed first to Australia. Yoshi had studied English in school but never actually utilized his skills prior to leaving. He hoped the phrasebook would be useful because he thought his skills were very low. However, much to his surprise, he was able to communicate better than expected when he got to Australia. Although it was difficult for him, he believed it was going to be much worse:

I thought for sure I would need to take the phrasebook with me everywhere I traveled and show the people what I wanted. But actually I didn't really use it for communicating, I just used it for studying [by] myself.

Realizing his English capabilities proved particularly important for Yoshi. After becoming aware that his skill was much better than he perceived it, he acquired newfound confidence in speaking the language and also in 
himself:

I started to gain more confidence from these experiences and I thought it was good for me. When I got off the plane, I was very weak and scared, but when I used my skills I slowly [gained] more confidence. By the end of my time in Australia, I was confident in myself. I really started to see myself differently and as a more interesting person that shouldn't be as sad as I was.

The implementation of Yoshi's English in real life contexts provided the impetus for his identity to change. His meaningful communications with Australians provided him the substance needed to conceptualize himself more positively.

Yoshi observed that further study and implementation of his skills continued to affect how he thought of himself. He subsequently spent another few weeks in Thailand, where he continued to study English and make use of his linguistic skills. Yoshi's trip to Thailand was particularly important for arriving at identity revelations:

It was in Thailand when I realized that I was different from other people in a good way. I was previously depressed and not happy with my life, but when I was traveling and using my English, I felt much better about myself. I think I feel who I am as a person. I liked having this international experience and was much happier when I thought of myself as more of an international person than as a typical Japanese. My life in Japan wasn't very successful, but [when traveling], I was somebody more successful and interesting. I wanted to be an international person since that time.

Yoshi's experiences abroad thus led to revelations regarding the way that he constructed his own identity in relation to others and how he saw himself in relation to other people in and outside of Japan. His saw his failures in Japan counteracted by his language success abroad. The more dynamic personality that he emerged with served as an important motivation for him to continue studying English and continue taking trips abroad, which he believes made him a more refined person.

An important element of Yoshi's experiences is that they led him to think differently of cultural Otherness. Not only was his own identity changed, so too were the ways that he conceptualized people from different backgrounds:

After I returned from my first trip, I wanted to become friends with more different types of people. I wanted to make international friends and use my English more in Japan. Before I left Japan, I never used English, but after traveling I tried to use it as much as possible. I started to go to international bars and clubs on the weekend just so I can talk to foreigners. I went there by myself. I would never have the courage to do this before. I met some foreign friends and have then had a good relationship with them. I understand them much better and I know much more about their lives and cultures now.

Like Shiori, foreigners in Japan became more accessible physically and conceptually. By befriending foreigners and using his English skills, Yoshi developed a new way of thinking about himself and his relationship to cultural Others. His experiences abroad encouraged him to continue having intercultural experiences at home in Japan and he sought to befriend foreign residents. Doing so also led him to see foreigners more positively:

Before making foreign friends, I never really had an impression about the foreigners in Japan. I knew there were some, but really I didn't care to know something about them. Then I went to Australia and Thailand, I made friends of different cultures, and I became interested. I wanted to know more. After making foreign friends here in Japan, I understand foreign cultures even more. Many foreigners living here need some help and I am able to offer it to them. This makes me feel really good. 
Yoshi emerged from these experiences with not only a more positive image of foreigners, but also a willingness to help them with the difficulties they faced in Japan. Had Yoshi not had such experiences abroad, where he engaged in meaningful interactions with people from different cultures, it is doubtful that such changes to his self-identity and the way he conceptualized others would have occurred.

A similar vignette comes from Takeyuki, a twenty seven year old male who is now residing in the northern United States. Takeyuki had many international friends and a foreign girlfriend when he lived in Japan and was always very interculturally minded. However, he noted that his experiences abroad were discernably different from those he had in Japan:

Interacting with foreigners in Japan was interesting at first. It was nice to talk with them and help them, but it is totally different from engaging with Americans in America. In Japan, I am kind of like a cultural authority and I need to talk with foreigners about Japan all the time. I don't care about Japan, I want to talk about other things too, not just Japan. I am other things besides a Japanese person. In America, I have much more freedom to talk and I don't feel restricted with what I can do. It is much better for me to make American friends in America than in Japan.

Although he also notes that North Americans often talk to him about Japan, and sometimes ask "dumb" questions, he says that does not mind it. He has enjoyed every moment of living abroad and operating in a foreign culture. It can be argued that Takeyuki lacked meaningful application of his English skills in Japan despite using them regularly. For his identity transformation to occur, it thus required him to utilize his skills in a new and more challenging context for him to arrive at future revelations about his identity.

These experiences changed Takeyuki more dramatically than the others. In his own words:

[My experience abroad] made me realized how I don't want to go back to Japan. I want to live in foreign countries and make my life somewhere else. I appreciate Japan and know it will be hard for my family, but that is not who I am. I am much happier in America and I have more interesting opportunities. If I stay in Japan maybe I [would] become a [businessman] or just some worker at some uninteresting place. In America, there are so many more opportunities and I can express myself freely and feel myself so much better. If I never went abroad for studying, I would have never known this.

Takeyuki's changes were quite radical compared to the others. His experiences led him to completely abandon his former identity and life in Japan and adopt an identity oriented towards his host country and its culture. Whereas Tetsu, Shiroi, and Yoshi remained oriented towards Japan with a stronger intercultural awareness, Takeyuki changed is orientation towards one directed towards foreignness.

Thus, there was a significant change in the way that Takeyuki recasted his identity after interacting with North Americans in North America. This identity and self-understanding differed qualitatively from the identity he asserted as an interculturally competent English speaker opearting from within Japan. The crucial role of practical and meaningful context propelled his identity progression. Takeyuki's implementation of his skills abroad provided an impetus for him to arrive at identity transformations heretofore unrecognized. He was unable to establish such an orientation towards being an international person without going abroad, living abroad, and feeling the sensations of what it is like to interact with non-Japanese people in their own environment.

\section{Discussion}

The data presented above raises several points worthy of further consideration. These points correspond to how the presented data pertains to the aforementioned literature and raise further implications for better understanding how language learning affects identity development. 
First, much of the data substantiates the aforementioned discussions about identity and its relationship to language learning. More specifically, it provides concrete examples of how self-understandings transform as learners progress through the study of a new language. All of the learners emerged from their experiences with a richer understanding of themselves and who they are as individuals. Learning and utilizing English was incorporated into their sense of personhood, which destabilized their former constructions of identity. In the case of Tetsu and Shiori, this was less profound, but, in the case of Takeyuki, this transformation was quite extreme. Takeyuki reoriented himself entirely towards a foreign cultural milieu and abandoned some elements of his former self. These identity products also engendered more fragmented understandings of self within the learners. Tetsu, for example, saw himself as someone who possessed more cultural capital than other Japanese and Yoshi saw his newfound interests in things foreign as evidence of more finely tuned cultural sensitivity. In short, much of the literature concerning language learning and its connection to identity construction resonates through the data above.

Second, this data reveals important information about how Japanese learners reconstructed their identity with greater orientation towards foreign Otherness; or in other words, how these learners developed a more "intercultural" identity. Although this interculturalness developed to varying degrees, each learner developed a greater orientation towards cultural Otherness as a result of their language study. This underscores what Gao (2007), Kim (1994), and Qu (2005) have all indicated, which is that binary understandings of identity are often inefficient to capture the nature personal identities. These works, as well as others from the literature review, explicate how identities become less restricted and increasingly open as they progress in their development. Thus, rather than seeing these learners as something other than Japanese, it is helpful to view them as having their orientation shifted in a way that incorporates a more intercultural character.

This point is substantiated by the fact that Japanese learners perceived foreigners as more physically and conceptually accessible after their intercultural experiences. Shiori and Yoshi explicitly mentioned the shorter distance they felt from cultural Others after their intercultural experiences. By engaging in meaningful interactions with members of the English speaking community, these individuals came to perceive cultural Otherness less distantly. They also all sought to continue engaging this Otherness and hoped that their comprehension of cultural Otherness would likewise expand as a result of their continued study and implementation of English skills. What this indicates is that by learning a new language and engaging in perceptually meaningful interactions with members of the target language community, learners can tangibly develop more diverse understandings of themselves but also engender new ways of conceptualizing one's self in relation to cultural Others. In this case, Japanese learners reconceptualized themselves with greater proximity to foreigners and cultural Others both in and outside of Japan.

Third, this paper draws further attention to the role of interaction in identity formation. Yihong Gao (2007, p. 108) has noted that "as identity is not simply a given but built through symbolic interaction, the use of language is entailed in the process of identity construction; the learning and use of a language other than the mother tongue is bound to have an impact on the person as a whole". While the ways identities change in relation to language study has heretofore been documented, as have the contents, there has been little writing on how this identity qualitatively changes due to language study. This paper suggests that language learners experience at least two discrete forms of identity change as they engage in the study of another language. The first arrives at the outset of language learning when learners seriously commit themselves to studying a new language and culture. Japanese learners that took to studying English as a means for them to construct a different self-image eventually realized these goals and began to see themselves more positively and as different from other Japanese. By actually taking English lessons and engaging in independent study, these actors developed an identity that they felt differentiated them from other Japanese.

However, the more dynamic understandings and greater cultural awareness that accompanied identity transformations occurred as a result of pragmatic and meaningful interaction. For example, Shiori observed that her self-understanding became qualitatively different after she engaged foreigners in interaction. Tetsu 
demonstrated that it was his work experience in Canada and struggling through the difficulties of living abroad that brought him to better understand his own experiences and his own identity. Likewise, Takeyuki and Yoshi noted that it wasn't until they went abroad and applied their skills in a context outside Japan did they realize the full effects of their identity transformation. Although these interactions differ in context and scope, there is a key point that resonates throughout: they all attained a more intricate, dynamic, and intercultural understanding of their identity and their relationship to diversity after the application of their skills pragmatically.

It must be observed that Takeyuki presents one curious example. His experiences helping foreigners, having a foreign girlfriend, and using English daily initially allowed him to create a sense of self that was particularly unique from other Japanese. However, it was not until when he went abroad that he said to have experienced a profound identity transformation. Although he used English pragmatically within Japan, these interactions became somewhat banal for him and the novelty of the situation had waned. In essence, communication lacked the meaningfulness extant in the other examples. Interacting with foreigners and helping them navigate life within Japan was no longer a challenge for him. From this, one can conclude that for identity changes to occur, interactions must be perceptually meaningful and participants in these encounters must recognize the more dynamic application of their acquired skills. Banal encounters may not provide the components necessary to induce the same types of identity changes within individual actors.

What this implies for the relationship between language study and identity development is that there must be greater attention paid to the process of identity development as it corresponds to different stages of learning. While this paper highlights two important conditions that allow learners to arrive at new understandings of their identity and their perceptions of others, there may in fact be other similar conditions and identity revelations that the learning process engenders. Whereas at the outset learners referenced their language study as a means of differentiate themselves from others, more profound changes happened when learners actually applied their skills in meaningful ways. A more intricate revelation of self-identity was only possible after such interactions had occurred. This indicates the important role that interaction plays in shaping identity but also that interactions in real time and that carry greater meaning outside the classroom are responsible for significant changes to personal identities.

\subsection{Implications}

When one considers the above data, and its relationship to extant theories, there emerge several important pragmatic and conceptual implications for teaching and learning languages. First, because this paper has highlighted that identities become less restricted as language learning and intercultural interactions unfold, it may be helpful for educators to take seriously the addition of more cultural material into the language classroom. This is a topic that has already received attention from numerous sources that have postulated a number of different ways culture should and could be taught in the language classroom (see Alptekin \& Alptekin, 1983; Byram, 1997; Byrd, Hlas, Watzke, \& Valencia, 2011; Cholpek, 2008; Davecha, 2003; Kramsch, 1995; Kuo \& Lai, 2006). Regardless of one's perspective on the definition of culture itself, it is clear that incorporating cultural lessons and information into the language curriculum will raise students' awareness of the culture on a broader level. Such cultural knowledge can readily be utilized pragmatically in regular conversation in ways that facilitate better communication across cultures and thus foster the development of interculturally centered identities.

Second, because identity transformations have been documented, and because this study suggests that these transformations happen at disparate stages, researchers and teachers can dedicate more attention to understanding the nature of these transformative processes. This can be achieved through systematic academic studies or through the assignment of critical assessments of self-identity in the language classroom. By better understanding the systematic ways that identities progress, educators can structure curriculums in ways that remain sensitive to these particular transformations. In effect, this will help learners and educators understand more meticulously how identity transformations unfold via the vehicle of learning another language. 
Third, these findings bring attention to the important role that the pragmatic application of language skills have for shaping identity developments. Since Japanese learners experienced further transformations after actually making use of their skills in perceptually meaningful ways, the role of interacting with other users of the language can be seen as an important impetus for arriving at identity realizations. Therefore, educators and curriculum planners can incorporate more chances for students to engage with other speakers of the target language so as to provide more opportunities for these identity developments to occur. By utilizing their skills in real life or real life-like environments, students can propel these changes to occur and provide a context that fosters constructive and reflective identity transformations.

\section{Conclusion}

This paper has intended to highlight several points. It has demonstrated the ways that Japanese learners' identities changed as a result of their language study. Particularly, learners developed a more interculturally oriented identity that permitted them to reconceptualize both themselves and cultural Otherness domestically and abroad. By studying a language and applying their linguistic skills, learners cut the pragmatic and conceptual distance between themselves and members of other cultures. This in effect, led them to develop more positive appreciations and understandings of cultural Otherness and allowed them to recast their own sense of self in a more dynamic way.

Additionally, this paper emphasizes and explains the important role of meaningful communication in cultivating these novel identities. While learners perceived their identities as having been affected by their initial study of English, much greater identity transformations to their self-understandings occurred after they had applied their skills in meaningful interactions. This paper postulates that the identity transformations that occur at the outset of language study and those that happen with the application of skills in meaningful interaction are of a qualitatively different nature. This indicates that greater connections need to be drawn between the process of identity change and its relation to different stages of language learning. Specifically, meaningful interactions at different scales may be requisite for more profound identity changes to occur.

As more and more people study foreign languages for a multitude of reasons, it is important to remain attentive to the ways learners are affected by their ongoing study. As shown, Japanese learners used their language training to effectively cut the distance between themselves and members of other cultural communities. This will have ramifications for future relationships that develop between foreigners and Japanese. Therefore, not only do these changes affect the learners themselves but they are also capable of changing the broader forms of sociality that develop within particular societies.

\subsection{Limitations}

This study exhibits two notable limitations. The first is its small number of participants. This study conducted interviews with just over thirty informants, which is a comparably low sample. Unlike quantitative studies, where hundreds or thousands of surveys may be disseminated, this qualitative study involved a much smaller number of participants. Thus, the generalizability of these findings may be limited. However, these findings reveal information that would otherwise not be ascertained by surveys and statistical data. This indicates that further studies can benefit from implementing mixed method approaches to more meticulously understand these process. Second, the findings here cannot be universally applied to every language learner. Since language learning is such a personalized experience, it is difficult to draw the conclusion that the trajectory of every person learning a new language might proceed down this particular path. This paper, rather than try to establish some universal rule, on the contrary has reported observations that have emerged from qualitative analysis. Future studies can build upon this foundation by incorporating a more progressive scale of identity construction into their own analyses. 
Acknowledgements: I would like to thank the following sources for helping to fund this research: the University of Iowa T. Anne Cleary Dissertation Fellowship, the University of Iowa Department of Anthropology, and the University of Iowa Center for Asia and Pacific Studies. Data gathered for this project has been approved by the University of Iowa's Institutional Review Board.

\section{References}

Alptekin, C., \& Alptekin, M. (1983). The question of culture: EFL teaching in non-English-speaking countries. ELT Journal, 38(1), 14-20. http://dx.doi.org/10.1093/elt/38.1.14

Bakhtin, M. (1981). The dialogic imagination: Four essays. (C. Emerson \& M. Holquist, Trans.). Austin: University of Texas Press.

Brown, H. D. (2000). Principles of language learning and teaching $\left(4^{\text {th }} \mathrm{ed}\right)$. White Plains: Addison Wesley Longman.

Burns, A., \& Roberts, C. (2010). Migration and adult language learning: Global flows and local transpositions. TESOL Quarterly, 44(3), 409-419. http://dx.doi.org/10.5054/tq.2010.232478

Byram, M. (1997). Teaching and assessing intercultural communicative competence. Clevedon: Multilingual Matters.

Byrd, D. R., \& Byrd, C. A. (2013). The role of dissonance and harmony in one L2 learner's identity development during a language camp experience abroad. The Journal of Language Teaching and Learning, 2, 40-57.

Byrd, D. R., Hlas, A. C., Watzke, J., \& Valencia M. F. M. (2011). An examination of cultural knowledge: A study of L2 teachers' and teacher educators' beliefs and practices. Foreign Language Annals, 44(1), 4-39. http://dx.doi.org/10.1111/j.1944-9720.2011.01117.x

Cholpek, Z. (2008). The intercultural approach to EFL teaching and learning. English Teaching Forum, 4, 10-19.

Cook, V. J. (2002). Second language acquisition: Portraits of the L2 user. Clevedon: Multilingual Matters.

Dalh, T. I., Clementi, D., Heysel, G. R., \& Spenader, A. J. (2007). Preparing young people to be lifelong language learners and users. In M. Mantero (Ed.), Identity and second language learning: Culture, inquiry, and dialogic activity in educational contexts (pp. 143-158). Charlotte: Information Age Publishing.

Davecha, L. (2003). Learning to be intercultural. In G. Alred, M. Byram, \& M. Fleming (Eds.), Intercultural experience and education (pp. 50-66). Clevdon: Multilingual Matters.

Dewaele, J. M. (2014). Second and additional language acquisition. In W. Li (Ed.), Applied linguistics (pp. 46-68). Somerset: John Wiley \& Sons.

Dörnyei, Z., \& Schmidt, R. (Eds.). (2001). Motivation and second language acquisition. Honolulu: University of Hawaii Second Language Teaching and Curriculum Center.

Duff, P. A. (2012). Identity, agency, and second language acquisition. In S.M. Gass \& A. Mackey (Eds.), The Routledge handbook of second language acquisition (pp. 410-426). London: Routledge. http://dx.doi.org/10.1017/S026719051400018X

Duff, P. A. (2015). Transnationalism, Multilingualism, and Identity. Annual Review of Applied Linguistics, 35 , 57-80.

Gao, Y. (2007). Legitimacy of foreign language learning and identity research: Structuralist and constructivist perspectives. Intercultural Communication Studies, 16(1), 100-112.

Hua, Z. (2014). Intercultural communication. In L. Wei (Ed.), Introduction to applied linguistics (pp. 112-128). Somerset: Wiley \& Sons.

Hulsen, M., de Bot, K., \& Weltens, B. (2002). Between two worlds: Social networks, language shift, and language processing in three generations of Dutch migrants in New Zealand. International Journal of the Sociology of Language, 153, 27-52. http://dx.doi.org/10.1515/ijs1.2002.004

Jenkins, R. (2008). Social identity. ( $3^{\text {rd }}$ ed.). London: Routledge.

Jackson, J. (2008). Language, identity, and study abroad: Sociocultural perspectives. London: Equinox Publishing. 
Intercultural identity transformations among Japanese learners of English

Kim, Y.Y. (1994). Beyond cultural identity. Intercultural Communication Studies, 4(1), 1-23.

Kim, Y.Y. (2001). Becoming intercultural: An integrative theory of communication and cross-cultural adaptation. Thousand Oaks: Sage.

Kim, Y.Y. (2008). Intercultural personhood: Globalization and a way of being. International Journal of Intercultural Relations, 32, 359-368. http://dx.doi.org/10.1016/j.ijintrel.2008.04.005

Kinginger, C. (2004). Alice doesn't live here anymore: Foreign language learning and identity reconstruction. In

A. Pavlenko \& A. Blackledge (Eds.), Identities in multilingual contexts (pp. 219-242). Clevedon: Multilingual Matters.

Klippel, F. (1994). Cultural aspects in foreign language teaching. Journal for the Study of British Cultures, 1, 49-62.

Kramsch, C. (1995). The cultural component of language teaching. Language, Culture, and Curriculum, 8(2), 83-92. http://dx.doi.org/10.1080/07908319509525192

Koven, M. (2007). Selves in two languages: Bilinguals'verbal enactment of identity in French and Portuguese. Amsterdam: John Benjamins Publishing Company. http://dx.doi.org/10.1075/sibil.34

Kuo, M., \& Lai, C. (2006) Linguistics across cultures: The impact of culture on second language learning, Journal of Foreign Language Instruction, 1(1), 1-10.

McEntee-Atalianis, L. J. (2014). Language, identity, and power. In W. Li (Ed.), Applied linguistics (pp. 172-190). Somerset: John Wiley \& Sons.

Norton, B. (2000). Identity and language learning: Gender, ethnicity and educational change. Essex: Longman.

Ochs, E. (1996). Linguistic resources for socializing humanity. In J. Gumperz \& S. Levinson (Eds.), Rethinking linguistic relativity (pp. 407-438). Cambridge: Cambridge University Press.

Pavlenko, A., \& Blackledge, A. (Eds.). (2004). Negotiating identities in multilingual contexts. Clevedon: Multilingual Matters.

Pavlenko, A., \& Lantolf, J. (2003). Second language learning as participation and the (re)construction of selves. In J. Lantolf (Ed.), Sociocultural theory and second language learning (pp. 155-177). Oxford: Oxford University Press.

Qu, W. G. (2005). On issues concerning English and identity research in China. The Journal of Chinese Sociolinguistics, 2005(2), 93-116.

Ricento, T. (2005). Considerations of identity in L2 learning. In E. Hinkel (Ed.), Handbook of research in second language teaching and learning (pp. 895-911). Mahwah: Lawrence Erlbaum.

Simon-Maeda, A. (2011). Being and becoming a speaker of Japanese: An autoethnographic account. Clevedon: Multilingual Matters.

Ting-Toomey, S. (1997). An intercultural journey: The four seasons. In M. Bond (Ed.), Working at the interface of cultures (pp. 202-215). London: Routledge.

Ting-Toomey, S. (2005). Identity negotiation theory: Crossing cultural boundaries. In W. B. Gudykunst (Ed.), Theorizing about intercultural communication (pp. 211-233). London: Sage.

Zaharna, R. S. (1989). Self-shock: The double-binding challenge of identity. International Journal of Intercultural Relations, 13, 501-525. http://dx.doi.org/10.1016/0147-1767(89)90026-6 
Capobianco, P. 